\title{
RAYMUNDO FAORO E AS LINHAGENS DO PENSAMENTO POLÍTICO BRASILEIRO ${ }^{1}$
}

Leonardo Octavio Belinelli de Brito é mestre e doutorando em Ciência Política pela Universidade de São Paulo (USP).

São Paulo, SP, Brasil.E-mail: <belinelli.leonardo@gmail.com>

http://dx.doi.org/10.1590/0102-069101/103

\section{Introdução}

Raymundo Faoro é tido como um dos grandes "intérpretes do Brasil", epíteto que se deve à interpretação histórica traçada em Os donos do poder, ensaio que publicou, em sua primeira versão, em 1958. Contemporâneo de Formação econômica do Brasil, de Celso Furtado, e Formação da literatura brasileira, de Antonio Candido - ambos publicados em 1959 - o principal ensaio de Faoro era já na altura de sua publicação, de alguma forma, extemporâneo, pois sua forma e sua ambição explicativa, que iam na contramão da especialização acadêmica dos livros de Furtado e Candido, colocavam-no mais próximo dos ensaios clássicos dos anos 1930.

\footnotetext{
1 Este artigo é fruto da dissertação de mestrado do autor, defendida na Universidade de São Paulo (USP) em 2015, sob orientação do professor Bernardo Ricupero. Uma primeira versão do artigo foi apresentada no $10^{\circ}$ Encontro da Associação Brasileira de Ciência Política, ocorrido em 2016 em Belo Horizonte, Minas Gerais. Nessa ocasião, o texto foi comentado pelos professores Juarez Guimarães (UFMG) e Jorge Chaloub (IBMEC-Rio), a quem o autor agradece.
} 
Mas o principal traço da extemporaneidade do ensaio faoriano residia na tese que sustenta: durante o auge do período nacional-desenvolvimentista - processo econômico e social que tomava o Estado como motor de desenvolvimento do país e o populismo como sua forma política -, o jurista gaúcho buscava as raízes dos males nacionais justamente na atuação do Estado, em sua visão calcada na lógica da dominação patrimonialista. Entre outros fatores, é provável que esta tese tenha sido decisiva para a pouca repercussão do livro de Faoro (Ricupero, 2007), a despeito de sua vitória no prêmio José Veríssimo, oferecido pela Academia Brasileira de Letras (ABL) em 1959.

Foi durante o período de vigência da Ditadura Militar inaugurada em 1964 que a percepção sobre o livro foi modificada. Publicado em uma edição consideravelmente ampliada em 1974 - que, como mostram Bernardo Ricupero e Gabriela Nunes Ferreira (2008), alterava alguns pontos da 70 tese defendida em 1958 -, Os donos do poder passava a ser considerado um livro de alto teor explicativo, pois tornava inteligível o processo de autonomização do Estado brasileiro em relação à sociedade, processo este que teria no regime militar então vigente seu momento mais recente e dramático. Sinal dessa mudança de visão sobre o ensaio foi sua adoção como uma das referências teóricas para as nascentes ciências sociais brasileiras (Werneck Vianna, 1999, 2010; Carvalho, 2011, Schwartzman, 1975, 1988, 2003), com destaque para a sua influência no campo disciplinar da ciência política. Esse fato se deve, ao menos em parte, ao seu uso pioneiro da sociologia da dominação de Max Weber, especialmente do conceito de "patrimonialismo", para "explicar o Brasil"2. Além disso, a militância de Raymundo Faoro pela redemocratização brasileira e por tudo aquilo que deveria

\footnotetext{
${ }^{2}$ Foi Sérgio Buarque de Holanda quem primeiro utilizou o arcabouço metodológico de Weber para “explicar o Brasil”, mas, diferentemente de Faoro, não utilizou sua sociologia da dominação. Para suas diferenças, ver Campante (2003).
} 
acompanhá-la, bem como sua atuação midiática, também emprestaram à persona pública do autor e ao seu principal livro um novo status.

Por tudo isso, compreende-se os motivos que tornaram o pensamento faoriano objeto de interesse acadêmico e político, especialmente ao longo do processo de institucionalização do campo de estudos conhecido como "pensamento político e social brasileiro". Entre os estudos sobre Faoro, há uma constante busca por compreender se existe em Os donos do poder, bem como nos demais escritos do autor, um programa político para o Brasil e, em caso afirmativo, qual seria sua natureza. Nesse sentido, cumpre observar que são várias as teses sobre o tema, e que o próprio Faoro não tornou mais fácil a missão de seus intérpretes. Por outro lado, a tese faoriana sobre o Brasil é meridianamente clara. Como entender, então, esse desencontro?

Embora se assente sobre esse terreno e, por isso mesmo, dialogue com as teses que entendemos serem as principais sobre a "utopia política" de Faoro, este trabalho tomará a tese de Gildo Marçal Brandão (2007) como eixo de sua discussão. Essa escolha se deve ao caráter provocativo da formulação de Brandão, que lança a hipótese da existência de algumas linhagens do pensamento político e social brasileiro - tese que busca tornar inteligível o desenvolvimento aparentemente errático desse pensamento. Nesse sentido, o autor vai além da própria obra faoriana e busca compreendê-la como continuadora da linhagem que denominou de "idealismo constitucional", da qual fariam parte autores como Tavares Bastos, Rui Barbosa, Assis Brasil, Simon Schwartzman, Bolívar Lamounier etc. Se é verdade que a discussão promovida por Brandão se direciona para a identificação do que denominava "formas de pensar", cabe

\footnotetext{
3 Tomo por empréstimo o termo usado por José Murilo de Carvalho (2005) em um de seus trabalhos sobre o pensamento político de Oliveira Vianna.
} 
ressaltar que a dimensão dos fins políticos almejados por esses autores está diretamente ligada à discussão sobre suas utopias, pois ela é um dos elementos que caracterizam seus pensamentos como "políticos". Nesse sentido, este artigo visa contribuir em dois planos distintos, mas articulados: ao mesmo tempo em que busca oferecer uma nova interpretação sobre a questão da "utopia política" de Faoro, almeja também aprofundar a reflexão sobre a proposta de pesquisa lançada por Brandão, a qual constitui uma das principais formulações sobre a história do pensamento político brasileiro, posição que ocupa ao lado dos estudos pioneiros de Wanderley Guilherme dos Santos e Bolívar Lamounier (Lynch, 2016).

Dessa forma, a nossa discussão sobre a "utopia política" faoriana partirá das interpretações presentes na bibliografia dedicada ao seu pensamento e de uma formulação nossa a esse respeito; em seguida buscaremos discutir se Faoro se enquadra na linhagem "idealista constitucional”, tal como sugeriu Brandão. No entanto, cabe destacar que não pensamos que o interesse em discutir tal questão esteja na formulação de uma suposta taxionomia do pensamento político brasileiro, cujo valor agregativo para o conhecimento seria duvidoso, mas sim na possibilidade de refletir sobre as especificidades da "interpretação do Brasil" de Raymundo Faoro, o que talvez torne possível compreender, simultaneamente, os fundamentos de seu pensamento político e as leituras feitas sobre ele. Assim, estaríamos em condições de oferecer uma interpretação nas duas dimensões aludidas, que, a nosso ver, deve conjugar os vários escritos faorianos, pois a despeito da variedade de temas tratados, parece haver neles uma problemática comum subjacente, resultando em uma linha argumentativa firme que os costura. Por isso, em contraste com o caminho mais comum, que prioriza a análise dos argumentos presentes em Os donos do poder, faremos uma revisitação de trabalhos menos conhecidos do autor, o que 
pode lançar nova luz a alguns problemas que a bibliografia sobre o seu pensamento já destacou.

$\mathrm{O}$ artigo está organizado da seguinte maneira: na sua primeira sessão, exporemos e discutiremos as principais teses sobre a "utopia política" faoriana, para formular uma interpretação do assunto; em seguida abordaremos a tese de Brandão sobre a tipicidade de Faoro como representante do “idealismo constitucional”. Por fim, faremos algumas considerações sobre o que entendemos ser os principais impasses da "interpretação do Brasil" de Faoro.

\section{Liberal-conservador, republicano ou melancólico? Leituras sobre a utopia política de Faoro e uma interpretação}

A questão a que chamamos de "utopia política" de Faoro é intimamente ligada ao seu diagnóstico sobre a história brasileira. Talvez o trecho em que tal entrelaçamento fique mais claro esteja em Existe um pensamento político brasileiro?, texto no qual, como observou Luiz Werneck Vianna (2009), as indicações sobre o projeto político faoriano ficam mais bem expostas. Analisando o período de crise da dominação lusitana sobre a sua principal colônia, Faoro destaca da seguinte forma a emergência das ideias acerca da independência desta última:

Uma vigorosa corrente subterrânea, que ameaçara aflorar contra os emboabas, hesitante mas viva contra os mascates, tímida e ativa na Inconfidência, emerge em 1817, no Recife. Adensa-a uma constante, já homogênea no começo do século XIX, estruturada na propriedade agrária, em conflito com a cúpula burocrática, vinculada ao comércio urbano e internacional, o comércio de raízes portuguesas. A aliança entre propriedade agrária e liberalismo, visível nos demagogos letrados, entrelaçada pelos padres cultos, pelos leitores dos enciclopedistas e pelos admiradores 
da emancipação norte-americana, ensaia seus primeiros e vigorosos passos, que darão os elementos de luta nos dias agitados de 1822 e expulsarão o imperador em 1831, incapazes, todavia, de organizar o Estado à sua imagem. 1817 não sugere um movimento malogrado, mas a amostra de uma tendência possível, como possível foi o processo de independência e de fragmentação do mundo americano espanhol (Faoro, 1987, p. 30).

Para os fins da discussão desse artigo, é decisivo o papel que o liberalismo desempenha nessa "vigorosa corrente subterrânea". Por um lado, essa corrente adotará um liberalismo mais genuíno do que o esposado pelos realizadores do processo de independência do Brasil que, em aliança com o setor que Faoro denominou "estamento burocrático", formularam um "liberalismo de transação". O primeiro liberalismo seria "mais genuíno" porque se interessaria em desconstruir o poder emanado da ordem política de matriz lusitana, enquanto aqueles que sustentavam o "liberalismo da transação" estavam mais interessados em construí-lo e aperfeiçoá-lo. Por outro lado, o autor reconhece que os liberais emancipacionistas componentes da corrente submersa mencionada, ao passo que eram a chance da construção de uma ordem política brasileira própria, eram na verdade forças anárquicas (Cf. Faoro, 2008b, p. 304). A tensão própria dessa corrente apareceria na conformação do pensamento político brasileiro. Ainda em Existe um pensamento político brasileiro?, Faoro a formula da seguinte forma:

o elemento nacional está no sentido certo; não se trata de um pensamento nacional, de um país como Nação, mas como núcleos não homogêneos, com um projeto - apenas como projeto nacional. As circunstâncias - a dissolução do sistema colonial, teriam configurado as bases de uma consciência histórica, estamental e virtualmente de classe, 
sem que se possa configurar uma situação revolucionária, pelo menos no seu momento inicial, pela ausência de projeto. Mas o quadro é um conjunto de possibilidades num processo difuso. Trata-se de uma consciência possível (Faoro, 1987, p. 35, grifos do autor).

Para tornar mais complexo o quadro, vale lembrar a observação de Bernardo Ricupero e Gabriela Nunes Ferreira (2008), que indicam a alteração de perspectiva faoriana sobre as possibilidades emancipatórias do Brasil ao longo do tempo: enquanto na primeira edição de Os donos do poder Faoro parece mais distante dos ideais que seriam encarnados pelo Partido Liberal do Segundo Reinado - partido que conteria alguns elementos da referida "corrente subterrânea", como a forte presença de senhores de terras -, na segunda edição do ensaio, publicada em 1974, haveria maior simpatia do jurista gaúcho com relação aos princípios esposados pelos liberais do Império, embora vislumbrasse, nesta altura, uma maior dificuldade para sua implementação.

Os trechos e argumentos citados acima ilustram a dificuldade de interpretar a relação entre a existência de um programa político e a possibilidade de sua realização no pensamento de Raymundo Faoro: ao passo que o autor valoriza a corrente emancipacionista, não deixa de assinalar a sua incompletude e mesmo a suposta derrota de seus epígonos na história política brasileira. Diante da dificuldade interpretativa que essa atitude desencantada impõe aos historiadores do pensamento político brasileiro, surgiram três interpretações sobre a maneira como esses dois polos se relacionam em seu pensamento.

A primeira, e talvez mais influente, é a de Luiz Werneck Vianna (1999, 2009), que é seguida por Jessé Souza (2000, 2015). Para o sociólogo carioca, Faoro representaria o campo liberal do pensamento político brasileiro, incluída aí a dimensão econômica. Nesse sentido, esse autor enfatiza a 
proximidade das interpretações do Brasil de Faoro e Simon Schwartzman, bem como a realização de seu programa político a partir dos anos 1990, período em que foram tomadas medidas para desconstruir o Estado brasileiro formado no período desenvolvimentista inaugurado em 1930. Em sentido diferente, Juarez Guimarães (2009) e Rubens Campante $(2003,2009)$ sublinham a dimensão normativa do pensamento faoriano, aproximando-o do que poderíamos chamar, seguindo os termos dos debates contemporâneos da teoria política, de republicanismo. Para Guimarães, "[Faoro] foi o primeiro entre nós a construir uma narrativa de longa duração a partir do critério de liberdade política, entendida em sua chave republicana, como autogoverno dos cidadãos autônomos" (2009, p. 80, grifo do autor).

Já a terceira posição é compartilhada por Ricupero e Ferreira (2005; 2008) e Gildo Marçal Brandão (2007); segundo eles, o pessimismo de Faoro, principalmente a partir da segunda edição de Os donos do poder, impediria a formulação de um programa político. Nos termos de Brandão:

Aqui [nos dois últimos parágrafos da primeira edição de Os donos do poder] a cisão entre o que deve ser e o que pode ser é completa, conclusão por assim dizer lógica de um teorema analítico altamente formalizado, que só consegue enxergar na realidade a dispersão do empírico, a acidentalidade da existência contraposta à essência imutável, e que em sua demonstração não procura ou não encontra no objeto investigado determinações ou indicações que permitam aproximar o imperativo categórico das circunstâncias concretas que os homens não escolheram para viver. Na ausência de mediações entre o que é e o que deve ser, o passado é fardo, o futuro tempestade. Uma vez que a esperança e razão, ética e história se desentendem, não há meio-termo e daí o desespero, que leva a uma posição revolucionária: fiat justitia pereat mundus. É bem 
verdade que esse radicalismo abstrato, do qual se poderia derivar ou uma Grande Recusa ou a aceitação resignada do existente, vem atenuado na edição de 1973, na qual o futuro é eliminado e o verbo, posto no passado, torna a posição menos apocalíptica, mas nem por isso submetida a menores tensões: o desespero cede lugar ao estoicismo e à melancolia. Diante do presente eterno, a consciência sabe que é inútil toda resistência e não obstante resiste, não se dobra diante do inevitável (Brandão, 2007, pp. 144-145).

Como observação preliminar, vale notar que a interpretação de Werneck Vianna ressalta a coerência do pensamento faoriano, a qual teria um diagnóstico eminentemente político (Werneck Vianna, 1999, 2009) para os males brasileiros e uma terapêutica correspondente e inversa à doença política que aflige o país: reduzir o espaço do Estado para permitir o fortalecimento da sociedade. Já Guimarães e Campante tendem a sublinhar os "fins" de Faoro, posição oposta à de Ricupero e Ferreira, que se apegam à narrativa histórica traçada pelo autor aqui estudado.

A nosso ver, a interpretação de Werneck Vianna é mais robusta no que se refere às possíveis implicações ideológicas das teses faorianas, mas não é firme o suficiente para encontrar respaldo nas letras de Os donos do poder ou de outras obras. No que se refere às implicações ideológicas, bastam dois exemplos para que o argumento seja comprovado. O primeiro é a tentativa de filiação que Antonio Paim (2000), elaborador do curso de formação política do partido Democratas (DEM) ${ }^{4}$ e adepto de posições liberais-conservadoras, tenta fazer entre a sua narrativa sobre a formação patrimonialista do Brasil e a narrativa faoriana. O segundo é citação feita por Joaquim Levy, economista ${ }^{4}$ A informação se encontra disponível em: <https://goo.gl/L1Zfjj>. Acesso em:
22 mar. 2018. 
ortodoxo formado na Universidade de Chicago e ex-ministro da Fazenda do segundo governo Dilma Rousseff, da tese de Faoro para embasar o seu programa de reformas econômicas (Levy, 2016). Já no que se refere às posições do jurista, o argumento de Werneck Vianna fica fragilizado quando lembramos as críticas de Faoro ao neoliberalismo (Faoro, 1993).

Por outro lado, tanto as formulações de Guimarães/ Campante como as de Ricupero e Ferreira/Brandão parecem seguir traços que podem ser rastreados nos diversos escritos faorianos. Por isso, é mandatório explicar como essas duas interpretações diferentes são simultaneamente razoáveis para interpretar o pensamento faoriano.

Nesse sentido, convém salientar que, como observam Brandão (2007) e Ricupero e Ferreira (2008), Faoro termina a segunda edição de Os donos do poder escrevendo com os verbos no passado, o que é determinante para a sensação de pessimismo passada pela obra. Por outro lado, os demais escritos faorianos - entre os quais se destaca Assembleia constituinte: a legitimidade recuperada (Faoro, 2007) - parecem mais distantes dessa posição. A diferença das disposições anímicas das duas obras citadas pode ser, ao menos parcialmente, explicada pelos diferentes papéis que o jurista desempenhava nos momentos nos quais as redigiu: enquanto Os donos do poder é obra de um intelectual que visa interpretar o sentido geral da evolução sócio-histórica do Brasil, Assembleia constituinte é um texto de um publicista em ação contra o seu presente. Essa diferença é decisiva para que compreendamos adequadamente os diferentes papéis que os clássicos da teoria política desempenham nos seus escritos. Como afirma Faoro em Os donos do poder, "estão presentes, nas páginas que se seguem, os clássicos da ciência política, Maquiavel e Hobbes, Montesquieu e Rousseau, relidos num contexto dialético" (Faoro, 2008b, pp. 13-14). Quer dizer isso, salvo erro, que as teses desses autores foram 
lidas, simultaneamente, positiva e negativamente; ou seja, o jurista procurava compreender de que maneira a formação política ibero-brasileira se encaixa nos exemplos, positivos e negativos, fornecidos pelos clássicos da teoria política. Para ficarmos no exemplo de Montesquieu, vale observar que o patrimonialismo ibérico se aproxima do despotismo oriental teorizado pelo autor de $O$ espírito das leis, principalmente porque em tal tipo de dominação não existem corpos intermediários - que poderiam ser os donos de terra liberais, segundo a narrativa faoriana -, o que, por sua vez, facilita o processo de dominação arbitrária. Não escapa ao leitor de $O$ espírito das leis a percepção de que há no livro certa contraposição entre Inglaterra (exemplo positivo) e Oriente (negativo). No caso de Os donos do poder, a constância da aproximação do caso luso-brasileiro com as características avaliadas negativamente pela tradição do pensamento ocidental já foi apontada de maneira crítica por Jessé Souza (2000) e Rubens Campante (2009).

Com isso, queremos dizer que os clássicos da teoria política aparecem, com signo diferencial em Os donos do poder, como ferramentas para a reflexão histórica. Já em Assembleia constituinte e Existe um pensamento político brasileiro?, os clássicos aparecem como balizas da discussão normativa empreendida pelo autor. É claro que no caso de uma reflexão com as características das de Faoro, não existe uma diferença essencial entre "reflexão histórica" e "reflexão normativa". O mais correto seria pensar que os diferentes escritos contêm diferentes gradientes desses elementos, sem que nunca um se sobreponha completamente sobre o outro. Sinal disso é que, se em Os donos do poder a reflexão normativa é deixada em segundo plano em prol da narrativa histórica, embora forneça o sentido de sua interpretação, ela aparece com mais força quando o jurista se debruça sobre aquelas que entende como as determinações do pensamento político brasileiro (Faoro, 1987) e atinge o seu ponto culminante no texto sobre a Constituinte. 
Como já indicamos, uma pista promissora para desvendarmos o programa político faoriano e sua posição diante dele está nas evidentes simpatias que Faoro nutria pelo liberalismo de matriz local que não chegou a ser formar completamente no Brasil ao longo do século XIX. Vimos que nesse período, para ele, vigoravam dois liberalismos no Brasil: o que continha um "elemento nacional" - esposado pelos donos de terras locais que defendiam um regime político descentralizado e republicano - e aquele que continha "elementos reacionários" - sustentado pelos comerciantes portugueses e pela burocracia estatal.

Segundo Faoro, o liberalismo nacional era fruto da crise do Sistema Colonial e se expressou num ciclo de revoltas de intensidades variadas, que começou pela Inconfidência Mineira (1789), passou pela repressão no Rio de Janeiro (1794) e pela Revolução dos Alfaiates na Bahia (1798) e se irradiou na primeira metade do século XIX, chegando até 80 a Revolta Praieira (1848) (Cf. Faoro, 1987, p. 35). Como já observamos, embora enfatize a incompletude da formulação dos pensamentos dos revoltosos, o jurista saudará o seu sentido político, pois ia na contramão das posições defendidas pelo Liberalismo que tinha como matriz a Revolução Portuguesa de 1820.

Um ponto especialmente digno de nota no interrompido processo de formação do pensamento político autenticamente liberal no Brasil teria sido a Inconfidência Mineira, movimento político organizado por senhores de terras que buscavam articular um projeto político em seu próprio benefício. Os revoltosos mineiros liam os confederalistas norte-americanos, bem como as constituições da Pensilvânia, Virgínia, Massachussets, New Jersey, Delaware e Maryland. Os conspiradores, que não estavam completamente cientes do desenvolvimento político norte-americano, cogitavam arranjo semelhante com São Paulo e Rio de Janeiro, "sem a ideia nacional", propondo um regime de viés municipalista. 
Em suma: para Faoro, os senhores de terras locais sofriam o peso do antigo Sistema Colonial, que então entrava em colapso e permitia, assim, brechas de resistência aos seus opositores. Reconhecendo que não se tratava de um movimento político popular, o jurista gaúcho argumenta que seu eventual sucesso teria aberto as portas para um desenvolvimento posterior, marcado pela incorporação dos segmentos mais fragilizados da população. Esse é um passo decisivo para compreender a argumentação faoriana.

A ausência de Liberalismo [...] estagnou o movimento político, impedindo que, ao se desenvolver, abrigasse a emancipação como classe da indústria nacional. Seu impacto revelaria uma classe, retirando-a da névoa estamental na qual se enredou. [...] O Liberalismo, ao se desenvolver autenticamente, poderia, ao sair da crisálida da consciência possível, ampliar o campo democrático que lhe é conexo, mas pode ser-lhe antagônico. Por meio da representação nacional - que é necessária ao Liberalismo - amplia-se o território democrático e participativo, conservando, ao superar, o núcleo liberal. [...] O socialismo, numa fase mais recente, partiria de um patamar democrático, de base liberal, como valor permanente e não meramente instrumental (Faoro, 1987, p. 55, grifos do autor).

Apesar da crise do antigo Sistema Colonial, a chegada da família real em 1808 teria selado o destino do pensamento político nacional, pois teria marcado a transação desigual, com o predomínio dos elementos reacionários, entre os dois liberalismos. Entretanto, o

elemento nacional [...] permaneceu vivo, apesar de nãodominante. Ele atua, na prática, no cerne do pensamento político, com a irrealizada superação. Irrompe, no curso 
da história, nos dois séculos, na dobra de todas as crises de sistema e de governo. A conjectura de um veio inesgotado permanece, portanto, atual e inexplicada, truncando o desenvolvimento de um pensamento político nacional, dinamicamente autônomo e capaz de levar a um estágio pós-liberal. (Faoro, 1987, p. 38)

Assim, se os inconfidentes liam os contratualistas e os enciclopedistas, além dos resultados concretos de seus pensamentos, corporificados na Declaração da Independência dos EUA e na Declaração dos Direitos do Homem - composição que Faoro chamará de "liberalismo radical" -, havia também os que o autor denominará "liberais irados", que se encontravam no Norte do país. Na Inconfidência Baiana de 1798, teria havido o surgimento de vozes populares, embora minoritárias, que ecoavam o jacobinismo francês. "Desta vez não haveria ambiguidades acerca da escravidão: todos seriam 82 livres" (Faoro, 1987, p. 40). Existiam insatisfações de setores discriminados, artesões, pardos, que viam como possível a aliança com os escravos. A revolta contestava a supremacia real, bem como reivindicava o comércio livre - a partir da inspiração de Adam Smith, lido pelo futuro Visconde de Cairu. Ademais, os senhores de engenho se manifestaram contra a exploração do capital usurário dos comerciantes portugueses. Sempre segundo Faoro, as leituras que fundamentavam tais demandas eram contrabandeadas em Minas, Rio, Pernambuco e Bahia. Lia-se Raynal, Condillac, Mably, Voltaire, os enciclopedistas e Júlia ou a nova Heloísa, de Rousseau. Em suma: "O extremo limite das reivindicações repousa na igualdade de direitos para todos, o que afasta qualquer precocidade socialista" (Faoro, 1987, p. 41).

Mas essas reivindicações teriam sido travadas com a vinda da família real em 1808, a qual impactaria também no destino do liberalismo nacional. Com a abertura dos portos, inspirada em Adam Smith - autor também revindicado pelos 
"radicais" e pelos "irados" -, houve o desligamento da relação entre liberalismo e emancipação nacional. Para Faoro, isso fez com que a "ala esquerda do Liberalismo" perdesse sua bandeira para a sua "ala direita" - "desligar-se-ia, desta sorte, a causa nacional da causa liberal" (Faoro, 1987, p. 42). A independência nacional, com o consequente problema de reconstrução do poder político do recém-fundado Estado brasileiro, reafirmaria o descolamento das duas causas. É bem verdade que houve resistências liberais ao projeto absolutista de Estado, como evidenciam as atuações de Cipriano Barata e Frei Caneca, que fundamentou sua resistência à carta constitucional de 1824 com base em Locke, Montesquieu e em Os federalistas. Caracterizando esse liberalismo, diz nosso autor:

Aí estará o radicalismo, cuja essência é o Liberalismo norte-americano e europeu, socialmente conservador.

O que importa acentuar é que esse Liberalismo não pôde, em nenhum momento, compatibilizar-se com o Estado brasileiro. Os liberais têm, com o poder, uma relação tempestuosa e ambígua: serão potenciais ou realmente sediciosos, ou, sem tocar no Estado, farão a política conservadora. Esta cisão está na base do pensamento político brasileiro e terá consequências que impedem o desenvolvimento, a adequação do pensar e o fazer. Melhor: de incorporar ao fazer o pensar (Faoro, 1987, p. 47 , grifo do autor $)^{5}$.

Aqui é preciso retomar o argumento do qual lançamos mão anteriormente: Faoro avalia de maneira positiva esse liberalismo - também conservador - porque identifica nele uma abertura em seus fundamentos para uma ordem social mais justa. Porém, o liberalismo que vigorará no Brasil

\footnotetext{
${ }^{5}$ Faoro sublinha o caráter não democrático da Declaração de Independência dos Estados Unidos e da Declaração dos Direitos do Homem em Assembleia constituinte: a legitimidade recuperada (Faoro, 2007).
} 
será outro, o qual não conteria tais frestas. Segundo Faoro, um dos seus representantes será o Conde de Palmela, que desfrutou da convivência e do aprendizado de Benjamin Constant e Madame de Staël. Ele será o formulador do "Liberalismo como tática do Absolutismo" (Faoro, 1987, p. 52). Essencialmente, nem ele, nem José Bonifácio, nem Hipólito da Costa, seriam liberais. São duas as marcas desse liberalismo não liberal: a ênfase na construção do Estado - na construção do Poder, portanto - e a busca por cindir Liberalismo e Democracia - fresta aberta pelos jusnaturalistas e seus descendentes (Faoro, 1987, p. 54).

Em suma:

a ossificação do modelo liberal, o absolutismo mascarado de D. João VI e de D. Pedro I, pela voz de seus intérpretes, desclassificou todas as concepções liberais autenticamente liberais. O Constitucionalismo, que se apresentou como sinônimo de Liberalismo, seguiu outro rumo específico, particularmente na Carta outorgada de 1824. O ciclo se fecha: o absolutismo reformista assume, com o rótulo, o Liberalismo vigente, oficial, o qual em nome do Liberalismo, desqualificou os liberais. Os liberais do ciclo emancipador foram banidos da história das liberdades, qualificados de exaltados, de extremados, de quiméricos, teóricos e metafísicos [...]. Seu liberalismo foi afastado, mas não superado, nem ultrapassou o estágio de consciência possível. Que significará a exclusão, hoje irrecuperável, em virtude de mudança da estrutura, da sugerência que o tornou um dia necessário? (Faoro, 1987, p. 54)

A relação entre Constitucionalismo e Liberalismo de matriz democrática reaparecerá em Assembleia constituinte: a legitimidade recuperada (Faoro, 2007), texto escrito quando Faoro era presidente do Conselho Federal da Ordem dos Advogados (OAB) do Brasil e lutava contra a proposta do 
general Ernesto Geisel, segundo a qual a transição do regime militar para o Estado de Direito seria feita por emendas à Constituição de 1967. Para demonstrar a inadequação da proposta do regime, o jurista realizou um estudo em que buscava defender os pilares do constitucionalismo moderno, que seriam as bases do regime democrático. Para o autor, no Brasil ocorreria o oposto: as constituições seriam meras armas de legitimação do poder político constituído. Faoro caracterizará essa situação como marcada pelo que chama de "constituição semântica", isto é: "Embora se aplique na sua plenitude, sua realidade não é senão a formalidade escrita da situação do poder político existente para o benefício exclusivo dos detentores de fato do poder, que dispõem, para executá-la, do aparelhamento coativo do Estado" (Faoro, 2007, p. 173). Por isso mesmo, aliás, este tipo de constituição não limita o poder, mas o estabiliza. Como se vê, aqui reencontramos a mesma estrutura-tese do "liberalismo de transição".

Como uma variação da constituição "semântica", teríamos aquele que Faoro denomina de constituição "nominal", a qual também serve para esconder o autoritarismo:

Há, neste caso, a desarmonia entre a situação de fato - a constituição social - e as normas constitucionais, tidas por prematuras, na versão conhecida da menoridade do povo. Com o tempo, pelo desenvolvimento de condições reais, a constituição viria a ser aplicada, reduzida, no presente, a um manual educativo. [...]. Enquanto esse dia não chega, os detentores do poder mandam e desmandam, também eles envoltos na confortável - confortável para eles - esperança do futuro, seja do país grande potência, do país rico ou do país educado (Faoro, 2007, p. 173).

Desse ângulo se compreende a ênfase dada pelo jurista ao conceito de "poder constituinte", usualmente deixado de lado, devido ao seu viés democratizante, nos debates 
constitucionais brasileiros. "No fundo do movimento constitucionalista reside a preocupação de desmascarar o despotismo - todas as formas de autocracia - pela identificação dos males e riscos do arbítrio" (Faoro, 2007, p. 174). Disso decorre, naturalmente, a preocupação com a legitimidade das leis, que só pode existir num processo constitucional em que haja harmonia entre o poder constituinte e o poder constituído.

Por sua vez, como se sabe, os autoritários costumam ser cientes da necessidade de legitimar o exercício do poder a que servem. Nesse registro, é especialmente instrutiva a análise que Faoro faz do Ato Institucional no 1 , de 9 de abril de 1964. Lê-se no documento citado: "A revolução se distingue de outros movimentos armados pelo fato de que nela se traduz, não o interesse e a vontade de um grupo, mas o interesse e a vontade da Nação" (BRASIL, 1964). Interpretando esse trecho, afirma o autor:

A revolução vitoriosa se investe no exercício do Poder Constituinte. Este se manifesta pela eleição popular ou pela revolução. Esta é a forma mais expressiva e mais radical do Poder Constituinte. Assim, a revolução vitoriosa, como Poder Constituinte, se legitima por si mesma. Ela destitui o governo anterior e tem a capacidade de constituir o novo governo. Nela se contém a força normativa, inerente ao Poder Constituinte. Ela edita normas jurídicas sem que nisto seja limitada pela normatividade anterior à sua vitória. Os Chefes da revolução vitoriosa, graças à ação das Forças Armadas e ao apoio inequívoco da Nação, representam o Povo e em seu nome exercem o Poder Constituinte, de que o Povo é o único titular (Faoro, 2007, p. 180).

Em contraposição às recorrentes usurpações da soberania popular, única fonte legítima de legitimidade, o programa político faoriano parece ser o de instituir uma ordem 
política que assente sua legitimidade na democracia. Nesse sentido, parecem corretas as caracterizações de Guimarães e Campante sobre o liberalismo de matriz democrática de Faoro; ao mesmo tempo, fica evidente o desencanto do autor acerca das possibilidades nacionais em $O s$ donos do poder e no conjunto de entrevistas reunidas em $A$ democracia traída (Faoro, 2008a), confirmando também as teses de Ricupero e Ferreira e de Brandão. Assim, a conclusão de Brandão, segundo a qual o fim de Os donos do poder é marcado por uma disjunção radical entre o "ser" e o "dever ser", pode ser ampliada para a totalidade resultante das reflexões de Faoro.

Em trecho desligado da articulação histórica, o jurista deixa mais claro o sentido normativo de seu pensamento.

A liberdade natural funda-se de maneira negativa: confunde-se à ausência de toda sujeição social e política. No momento em que a liberdade natural se converte em liberdade política, a exclusão alcança apenas uma categoria especial de vínculos, perdendo a sua significação qualificadamente negativa. A questão da liberdade política recebe, dessa maneira, uma formulação definida: como será possível sujeitar-se a uma ordem social e permanecer livre? Só uma resposta é possível, resposta que suscita uma solução democrática, ao estabelecer a medida em que a liberdade individual se harmoniza com a vontade coletiva, concretizada em uma ordem social. A liberdade política não se reduz a outra realidade senão à voluntária participação no universo das relações sociais. O que entendemos por liberdade política é, dessa forma, no fundo, a autonomia. A autodeterminação só porque é autonomia se expressa pelo consentimento, embora sofra limites e restrições necessárias. A mais importante dessas restrições se refere ao princípio da maioria, na qual a decisão se fundamenta. Como já se assinalou, o princípio majoritário não se identifica com o domínio 
absoluto da maioria, em uma ditadura que, se instalada, anularia sua própria base. Autonomia, como decantação da liberdade, no ponto que prevê a aprovação e o consentimento, sugere a existência da opinião pública, que, por sua vez, reclama, para existir, as liberdades de palavra, de imprensa e de cultos, com o suporte na liberdade básica entre todas, a liberdade física. Democracia se compatibiliza, por obra da necessidade conceitual, com o liberalismo político, desligado, nesse raciocínio, do liberalismo econômico (Faoro, 2007, pp. 212-213, grifo nosso).

Para utilizarmos os termos de Isaiah Berlin (2002), Faoro argumenta que a "liberdade negativa" só pode ser adquirida pelo uso legítimo da "liberdade positiva", o que o aproxima daquilo que a teoria política contemporânea chama de "republicanismo" (Silva, 2008). Assim, no pensamento faoriano há uma contraposição básica entre liberdade/poder legítimo versus poder despótico/falta de liberdade. Desse ponto de vista de torna compreensível o necessário casamento, para o jurista, entre liberalismo e democracia.

\section{0 idealismo constitucional e o "lugar" de Faoro nessa tradição}

Para iniciarmos a discussão sobre o "lugar" de Faoro no chamado "idealismo constitucional”, convém destacar a formulação de Brandão sobre o assunto:

A primeira delas [hipóteses a serem investigadas] é se é possível - sem prejuízo de suas mediações internacionais e sem deixar de atentar seja para a especificidade teórica de cada um desses autores, seja para a diversidade de contextos históricos nos quais eles atuam - situar o liberalismo atual em uma linha de continuidade que vem do diagnóstico de Tavares Bastos sobre o caráter asiático e parasitário que o Estado colonial herdou da metrópole portuguesa, passa pela 
tese de Raymundo Faoro segundo a qual o problema é a permanência de um estamento burocrático-patrimonial que foi capaz de reproduzir secularmente, e desemboca, como sugere Simon Schwartzman e outros "americanistas", na proposta de (des)construção de um Estado que rompa com sua tradição "ibérica" e imponha o predomínio do mercado, ou da sociedade civil, e dos mecanismos de representação sobre os de cooptação, populismo e "delegação" (Brandão, 2007, pp. 33-34).

A partir desse modo, é possível extrair algumas características básicas dos "idealistas constitucionais": i) enfatizam uma explicação política para a má formação do Brasil, pois atribuem ao Estado o papel de vilão de nossa história; ii) como consequência, acentuam a importância de uma reforma do Estado, o que iii) ressalta a crença que têm na força das leis, que poderiam mesmo reformular as práticas que lhe contrariam; iv) ainda como consequência do diagnóstico, valorizam as instâncias não-estatais - sociedade e/ ou mercado - como locus das virtudes e daí Brandão, utilizando um conceito reformulado por Werneck Vianna, denominar essa utopia como "americanista". Vistas em conjunto, não é difícil identificá-las como teses que regeram boa parte do ideário liberal que prevaleceu nos anos 1990 no Brasil.

Brandão também assinala que entre o pertencimento dos autores às linhagens do pensamento político brasileiro que identifica e as suas posições ideológicas não há necessária correspondência. Em outros termos:

Podemos ver em situações como estas misturas menos ou mais consistentes de ética de esquerda com epistemologia de direita, e vice-versa, polarizações ambíguas ou conciliações produtivas, sublimes coerências ou ecletismos maltemperados, mas o importante é não transformar as "afinidades eletivas" entre idealismo orgânico e 
conservadorismo, entre idealismo constitucional e liberalismo, entre materialismo histórico e socialismo, em vias de mão única, relações de causa e efeito ou homologias entre ideologias e posições políticas - até porque toda concepção de mundo é um campo de forças, mantém relações e ramificações em vários grupos sociais e manifestações espirituais (Brandão, 2007, p. 39).

Pensamos, no entanto, que essa ressalva de Brandão não se sustenta plenamente no caso do idealismo constitucional, pois a estrutura de reflexão desses autores os conduz para o ideário liberal. Por outro lado, "liberalismo" é um conceito amplíssimo e, nesse sentido, é plenamente possível que idealistas constitucionais adotem versões diferentes, e mesmo opostas, de liberalismos. Daí a necessidade de discutir o conteúdo de seus pensamentos. Ainda assim, é possível destacar algumas características que circunscrevem 90 um "conteúdo mínimo" do que se poderia chamar genericamente de liberalismo: a) ênfase na igualdade jurídica formal; b) simpatia pelo capitalismo com "espírito" moderno; c) defesa do regime liberal-democrático representativo e d) defesa da descentralização do poder político, com vistas à sua contenção.

Esquematizando provisoriamente: o termo "idealismo constitucional" não designa imediatamente uma "utopia política", mas a contém na medida em que é uma forma de pensar que articula um diagnóstico das razões da má formação nacional e os meios necessários para a sua superação; nesse sentido, tem afinidade com o que poderíamos chamar genericamente de "liberalismo", esse sim uma utopia política tout court.

Sinais desse vínculo estão nas simpatias dos autores vinculados ao "idealismo constitucional" pela experiência sociopolítica norte-americana, que é convertida em modelo para país. Sem se confundir com o "liberalismo" e com o 
"idealismo constitucional", o "americanismo", tomado na formulação de Werneck Vianna (1997), em certo sentido contempla também uma reflexão em torno de uma utopia política. Tanto é assim que a reflexão desses intelectuais sobre o Brasil costuma assumir a seguinte forma: como repetir o sucesso norte-americano? - Via de regra, os idealistas constitucionais argumentam que seria necessário rompermos com a nossa matriz política ibérica, vista como sustentadora de uma ordem política na qual o Estado ocupa o lugar central.

Esclarecidos alguns conceitos, é preciso que nos voltemos, novamente, para a narrativa histórica de Faoro sobre o desenvolvimento da relação entre liberalismo e a vida política nacional. Como vimos, a Independência foi, ao lado da vinda da família real em 1808, um dos momentos nos quais se divorciaram o liberalismo político e o liberalismo econômico, agora adotado pelas camadas do estamento burocrático. Algo análogo ocorre, segundo Os donos do poder, no caso da Primeira República. Note-se que embora Faoro seja um crítico do liberalismo econômico, argumenta que, em dados momentos da história, ele se conjugou, de maneira progressista, com o liberalismo político. Assim, num primeiro momento, ambos deveriam se realizar para, em seguida, as suas contradições serem resolvidas pela prevalência das dimensões democráticas do liberalismo político sobre as dimensões antidemocráticas do liberalismo econômico. Disso poderia surgir o "estágio pós-liberal”. De passagem e com cautela, talvez fosse o caso de aproximar essa posição de Faoro de uma certa herança hegeliana. Em favor da hipótese, anotemos um trecho de uma entrevista concedida a Jair dos Santos Júnior, na qual conta sobre o período em que escreveu a segunda edição de Os donos do poder: "É que naquele período quando eu escrevi o livro eu estava muito hegeliano. Talvez perceba isso em relação ao livro A lógica, do Hegel. E eu devorei aquilo" (Faoro; Santos 
Júnior, 2009, p. 110). Isso porque há certa filosofia da história informando o seu pensamento. Vejamos.

Se observarmos com atenção, poderemos notar que o caminho percorrido pelo liberalismo político na Europa Ocidental moderna informa de maneira decisiva a maneira como a qual Faoro interpreta os descaminhos do liberalismo no Brasil. Tomemos o caso inglês como exemplo. Lá, a liberdade política - ainda elitista - e a liberdade econômica foram fatores chaves para a dinamização do processo capitalista e para a implantação dos valores políticos, sociais e culturais modernos. Com a contradição entre o desenvolvimento capitalista e as condições precárias da vida das massas populacionais, surgiram movimentos reivindicativos que apelavam para os valores cristalizados pela modernidade como fundamentos para impedir o avanço indiscriminado da exploração capitalista. Ou seja, para a realização dos valores prometidos pela modernidade, era preciso reorganizar 92 a ordem social, incluindo nela a democratização do poder político e o acesso a bens materiais.

No Brasil essa relação não existiu, pois o liberalismo econômico estaria no campo dos "modernizadores", isto é, do estamento burocrático, enquanto o liberalismo político, semente da qual pode florescer a emancipação, estaria isolado. Assim, Faoro assinala que patrimonialismo e liberalismo econômico podem coincidir na realidade, apesar de seus princípios serem contrapostos (Faoro, 1993) - "O liberalismo econômico, para salvar seus fins, divorcia-se frequentemente do liberalismo político, entregando, em renúncia à autodeterminação, aos tecnocratas e à elite a condução da economia" (Faoro, 2007, p. 197). Ou seja, o autor vai na contramão daqueles que veem a implantação de medidas economicamente liberais como solucionadoras de nossos dilemas. É este casamento frustrante o responsável pelo pessimismo faoriano, corretamente assinalado por vários autores (Brandão, 2007; Ricupero; Ferreira, 2008; Guimarães, 2009). 
A partir desse eixo analítico podemos compreender a diferenciação que o jurista faz entre "modernização" e "modernidade", com ambos os termos sendo tomados em sentidos propriamente políticos. Enquanto na "modernização" as medidas políticas surgem no Estado e são tomadas sem fundamentação social - movimento, portanto, análogo ao da usurpação da soberania popular -, na "modernidade" as medidas são tomadas pelo caminho oposto; isto é, são construídas socialmente até chegarem ao Estado (Faoro, 1992), de maneira que é fácil perceber a sua afinidade com a ideia de soberania popular.

Percebe-se, então, que a explicação faoriana sobre a má formação social brasileira é política, mas não é, ao nosso ver, institucional, como afirmam Werneck Vianna (1999) e Campante (2005). Isto porque o termo "institucional" poderia não só restringir o alcance da ideia de "política", como poderia sugerir a impressão de uma suposta escolha metodológica de Faoro. Na verdade, ocorre que o tom normativo e filosófico de Faoro nos leva para outros lados, os quais um recorte do tipo sugerido pelo institucionalismo não daria conta. Por exemplo, como observa Campante, Faoro "analisa as questões políticas, econômicas e sociais da história brasileira sob a ótica dos direitos intrínsecos e inalienáveis do homem" (2009, p. 126).

Nesse sentido, pode-se aproximar Faoro do "americanismo", no que também se aproximaria de certos valores compartilhados pelos idealistas constitucionais. Com efeito: em seu pensamento existem ênfases nos direitos individuais, na defesa da ideia moderna de soberania popular - base para uma política efetivamente democrática, na aposta numa certa dimensão civilizatória do capitalismo moderno, com suas ressalvas, e a ideia de uma esfera privada alargada. Ao mesmo tempo, existe a ênfase na soberania popular e na sua dimensão de prática à moda da "liberdade positiva", o que certo liberalismo negará (Constant, 1985). Nesse sentido, 
Faoro valorizará o espaço público como instância mediadora entre o Estado e o espaço privado e disso decorre sua ênfase na ideia de "sociedade civil". Por outro lado, no âmbito econômico, o autor não se aproxima dos "americanistas" latino-americanos, que, como Tavares Bastos, apostavam no agrarismo como via modernizadora. Por isso, parece-nos equivocada a aproximação feita por Werneck Vianna (2009) entre Faoro e o autor de Os males do presente e as esperanças do futuro, pois embora criticasse, como o publicista alagoano, a forma dependente do Estado de nossa industrialização, Faoro tomava o partido da indústria moderna e não da indústria agrária.

Para sintetizar: no que se refere à proximidade com o idealismo constitucional, em Faoro encontramos uma explicação política para os males do país, mas não encontramos uma aposta acrítica nas possibilidades de reformas institucionais como soluções para nossos problemas. Isso porque, em certo sentido, essa tese não dá conta da possibilidade de que tais reformas sejam feitas para que tudo continue como antes, para usarmos a ideia clássica formulada por Giuseppe Tomasi di Lampedusa em O gattopardo (Di Lampedusa, 2007). Em outras palavras, o ceticismo faoriano acerca das modernizações brasileiras parece não combinar inteiramente com a fé dos idealistas constitucionais no papel exercido pelas leis. Isso porque Faoro enfatiza a centralidade da forma de surgimento das reformas necessárias, pois é ela que determinaria o grau de ruptura com a matriz ibérica de nossa formação. Ou seja: o liberalismo brasileiro, como exemplifica o caso do "liberalismo da transação", sinalizaria, repetidamente, com falsas rupturas. Por esse ângulo, chegamos à conclusão de que Faoro sugere que o liberalismo e o patrimonialismo não se opõem estritamente e podem se combinar na prática, ainda que a teoria exponha algo diverso. Em seus momentos mais sombrios, nosso autor parece sugerir que essa combinação é responsável por uma 
corrupção irreversível do poder político brasileiro. Desse modo, podemos sublinhar, seguindo as pistas de Werneck Vianna (2009), o contraste entre Faoro e Tavares Bastos, que enxergava na descentralização do poder - via instituição do federalismo - uma solução para a má organização política do país. É claro que se pode atribuir às diferentes experiências históricas vividas pelos dois autores tal diferença de posicionamento. Em outros termos: Tavares Bastos não podia tomar posição similar à de Faoro porque não viu a evolução histórica que o jurista gaúcho analisou. Ainda assim, convém sublinhar a diferença entre ambos, porque ela pode abrir caminho para refletirmos os impasses históricos que as formas de pensar enfrentam ao serem atualizadas pelos autores.

Para a complexificação da compreensão do pensamento faoriano, parece fazer sentido trazer à tona a formulação de Brandão sobre o que chamou de "pensamento radical de classe média” (Brandão, 2007). Embora não tenha desenvolvido com mais profundidade os traços dessa outra linhagem do pensamento político brasileiro, citar sua caracterização: "talvez não seja exagerado caracterizar esse pensamento democrático como socializante, quase sempre socialista, de matriz liberal, por vezes constitucionalista” (Brandão, 2007, p. 38). Dito isso, vale notar que o pensamento de Faoro contém uma ênfase democrática, bem como uma certa aposta num estágio "pós-liberal" (um socialismo liberal?) ${ }^{6}$, é de matriz liberal e é substantivamente constitucionalista. Talvez se possa assinalar que, em contraste com a ênfase do liberalismo no idealismo constitucional, o pensamento radical de classe média tem sua marca definidora na democracia e, dessa maneira, talvez vislumbre, ainda que de maneira dispersa, uma ordem social regida por valores humanistas e sem a prevalência dos ditames

\footnotetext{
${ }^{6}$ Como recorda Luiz Bernardo Pericás (2010, p. 39), o liberal italiano Piero Gobetti também compreendia que haveria uma sequência lógica entre liberalismo e socialismo, de maneira que seria interessante, para estudo futuro, comparar essa postura com a de Faoro.
} 
da modernização capitalista. Voltando ao âmbito da análise do pensamento político brasileiro, cabe ainda destacar que, como assinala o mesmo Brandão, "tais formas de pensamento não foram ou nem sempre são necessariamente excludentes entre si” e que "em vários [autores] vivem almas contrapostas e nem sempre a proclamada é a real” (Brandão, 2007, p. 38). Este parece ser precisamente o caso de Faoro.

\section{Alguns impasses da "interpretação do Brasil" de Raymundo Faoro}

Como é natural a todo pensamento político, o faoriano também é objeto de críticas variadas. Dentre elas, são especialmente interessantes aquelas que, partindo de observações "internas" ao seu pensamento, sublinham alguns limites que interessam entender não só por se tratar de um desafio da história intelectual, mas também por dizer respeito ao processo histórico-político brasileiro de modo mais amplo.

Nesse sentido, destaca-se a observação de Campante segundo a qual a interpretação de Faoro sobre o Brasil é baseada em uma

visão essencialista, que absolutiza as experiências históricas e que, incorporando as noções eurocêntricas de tradição e de modernidade, aposta tudo no conceito de patrimonialismo estamental tradicional para explicar nossa realidade, deixando de perceber algumas nuanças e especificidades de nosso passado e presente (2009, p. 126).

Jessé Souza (2000) segue linha de raciocínio similar para argumentar que Faoro teria uma explicação negativa do país, isto é, analisaria a trajetória nacional como um caso desviante da rota ocidental moderna, de maneira que não haveria uma compreensão "interna" a essa própria trajetória.

Sem negar completamente essas argumentações, vale registrar que os pilares dos direitos civis, políticos e sociais 
modernos foram formulados na Europa Ocidental durante a chamada Época Moderna, e se são tomados como referenciais analíticos para estudar a história do Brasil, parece ser inevitável a referência do exemplo. Mais especificamente, se a "liberdade política" é tomada como critério central para pensar sobre o país, a reflexão negativa não é arbitrária, dado que é imposta pela matéria analisada. Por outro lado, parece ser um reducionismo desprezar a dimensão negativa como motor analítico e explicativo - embora essa dimensão não deva ser a única.

Pensamos que a reflexão multifacetada de Faoro sobre o Brasil chegou à "inteligência da forma" de uma explicação de matriz liberal sobre o país, e não à toa tem, como observou Renato Lessa (2009), a forma de um pesadelo. Em outros termos: trata-se de uma análise que busca investigar os motivos das repetições das mesmas estruturas de poder, dos mesmos problemas e das mesmas soluções. Ora, é dessa imagem que surge a ideia de uma "viagem redonda", título da sessão final de Os donos do poder. Ocorre que, às vezes, a métrica, a história e as aspirações políticas não se combinam e a análise desse desencontro pode ser um ganho intelectual ao seu modo. Assim, a coerência e as tensões do pensamento faoriano podem ser mais bem apreendidas se tivermos em mente a dificuldade que um pensamento liberal-iluminista enfrenta para analisar os desdobramentos históricos luso-brasileiros. Faoro foi um liberal que compreendeu que o liberalismo estava, para usar uma expressão consagrada, "fora de lugar" (Schwarz, 2012). Nesse sentido, se aproxima mais de Francisco José de Oliveira Vianna do que, por exemplo, de Rui Barbosa, liberal como ele. Porém, ao contrário de Oliveira Vianna, esse diagnóstico - e eis um ponto de sua originalidade - não o leva a abandonar o ideário liberal iluminista, o que lhe custa a oscilação entre o

7 O termo é de Roberto Schwarz (1997), que o aplicou em contexto diverso. 
niilismo e a radicalidade progressista. Assim, a negatividade faoriana é prova de consequência com seus próprios pressupostos - coerência que se demonstra na disposição de chocá-los com a dura realidade dos fatos. Se se pode apontar que há certo "principismo" na sua posição, o que poderia ser reprovado caso o autor fosse um político, não é menos exato sublinhar que Faoro está no lugar da crítica da ordem social brasileira e não da sua apologia, como sugere, por exemplo, Souza (2015). Nesse sentido, ainda que a narrativa histórica faoriana não seja pontualmente exata, é difícil contestar que, ao seu modo, o jurista gaúcho atingiu um ponto nevrálgico do mal-estar dos brasileiros com sua política. Ainda no campo das possibilidades, cabe pensar que talvez venha daí a popularização do termo "patrimonialismo" para pensar a cultura política brasileira - chave de pesquisa que pode, por assim dizer, "atualizar" os insights faorianos (Carmo, 2011).

Mesmo levando isso em conta, cumpre registrar que a marginalização de temas como o exclusivo agrário e a escravidão parece comprometer a análise histórica de Faoro. Aliás, frise-se que é possível pensar que tanto o problema agrário como o da integração social dos negros e índios são, em parte, frutos de um poder político autocrático que logrou se manter efetivo ao longo do tempo, a despeito das variações de sua forma. A ausência de reflexões nesse sentido torna a narrativa faoriana como que tematicamente incompleta e, por isso, parcial. De algum modo, seguindo a ideia de Werneck Vianna (1997, 2009), é possível dizer que Faoro se prendeu talvez demasiadamente à esfera política e não avançou em seus impactos sociológicos.

Ainda assim, cabe destacar que a profundidade da reflexão do jurista sobre o liberalismo brasileiro é bastante particular, principalmente por estar justamente no seu campo. Trata-se, em suma, de um liberalismo crítico. E se Faoro logrou formalizar a narrativa liberal mais consistente sobre 
o Brasil - afirmação que tem como prova a gama de seguidores que ela conquistou e a sua importância no debate acadêmico e político brasileiro -, a constatação da impotência da ordem liberal no país e de seu constante oportunismo a torna, também, uma de suas melhores críticas.

\section{Leonardo Octavio Belinelli de Brito}

é mestre e doutorando em Ciência Política pela Universidade de São Paulo (USP). É o autor de Dilemas do patrimonialismo brasileiro: as interpretações de Raymundo Faoro e Simon Schwartzman (Alameda; Fapesp), no prelo.

\section{Referências}

BERLIN, Isaiah. 2002. Dois conceitos de liberdade. In: HARDY, H.;

HAUSHEER, R (orgs). Estudos sobre a humanidade. São Paulo:

Companhia das Letras.

BRANDÃO, Gildo Marçal. 2007. Linhagens do pensamento político brasileiro.

São Paulo: Hucitec.

BRASIL. 1964. Ato Institucional nº 1. Presidência da República. Casa Civil.

Distrito Federal. 9 de abril de 1964.

CAMPANTE, Rubens Goyatá. 2003. O patrimonialismo em Faoro e Weber e a sociologia brasileira. Dados, Rio de Janeiro, v. 46, n. 1, pp. 153-193. 2009. Raymundo Faoro: Brasil, política e liberdade. In:

GUIMARÃES, Juarez. (org.). Raymundo Faoro e o Brasil. São Paulo:

Fundação Perseu Abramo.pp,125-148.

CARMO, Andréia Reis. 2011. Patrimonialismo: o retorno ao conceito como possibilidade de compreensão do sistema político brasileiro por meio da abordagem da Cultura Política. Dissertação de Mestrado em Ciência Política, Faculdade de Filosofia, Letras e Ciências Humanas, Universidade de São Paulo, São Paulo.

CARVALHO, José Murilo. 2005. A utopia de Oliveira Vianna. In:

(org.). Pontos e bordados: escritos de história e política. Belo Horizonte: UFMG. pp.202-231. 2011. A construção da ordem e teatro de sombras. Rio de Janeiro:

Civilização Brasileira.

CONFIRA a íntegra do discurso de posse do novo ministro da Fazenda, Joaquim Levy. 2016. Ministério da Fazenda, Brasília, DF, 23 jun. 2016. Disponível em: <https://goo.gl/iobo71>. Acesso em: 22 mar. 2018. 
CONSTANT, Benjamin. 1985. Da liberdade dos antigos comparada à dos modernos. In: ZARKA, Yves Charles. (org.). Filosofia política. Porto Alegre: L\&PM. v. 2, pp. 9-25.

DI LAMPEDUSA, Tomasi. 2007. O gattopardo. Rio de Janeiro: BestBolso. FAORO, Raymundo. 1987. Existe um pensamento político brasileiro? Estudos Avançados, São Paulo, v. 1, n. 1, pp. 9-58. 1992. A questão nacional: a modernização. Estudos Avançados, São Paulo, v. 6, n. 14, pp. 7-22. . 1993. A aventura liberal numa ordem patrimonialista. Revista USP, São Paulo, n. 17, pp. 14-29. 2007. Assembleia constituinte: a legitimidade recuperada. In: A república inacabada. São Paulo: Globo. pp. 127-201.. . 2008a. A democracia traída. São Paulo: Globo. 2008b. Os donos do poder: formação do patronato político brasileiro. 4. ed. São Paulo: Globo.

FAORO, Raymundo; SANTOS JÚNIOR, Jair. 2009. Entrevista com Raymundo Faoro: uma viagem ao universo intelectual do autor. In: GUIMARÃES, Juarez. (org.). Raymundo Faoro e o Brasil. São Paulo: Fundação Perseu Abramo. pp.91-123.

GUIMARÃES, Juarez. 2009. Raymundo Faoro, pensador da liberdade. In: (org.). Raymundo Faoro e o Brasil. São Paulo: Fundação Perseu Abramo. pp.77-90.

LESSA, Renato. 2009. O longínquo pesadelo brasileiro. In: GUIMARÃES, Juarez. (org.). Raymundo Faoro e o Brasil. São Paulo: Fundação Perseu Abramo.pp. 63-76.

LYNCH, Christian. 2016. Pensamento político brasileiro: conceito, história e estado da arte. In: AVRITZER, Leonardo; MILANI, Carlos; BRAGA, Maria do Socorro. (orgs.). A ciência política no Brasil: 1960-2015. Rio de Janeiro: FGV. pp.275-320.

PAIM, Antonio. 2000. Quatro momentos decisivos da história do Brasil. São Paulo: Martins Fontes.

PERICÁS, Luiz Bernardo. 2010. Prefácio. In: MARIÁTEGUI, José Carlos. As origens do fascismo. São Paulo: Alameda. pp.7-59.

RICUPERO, Bernardo. 2007. Sete lições sobre as interpretações do Brasil. São Paulo: Alameda.

RICUPERO, Bernardo; FERREIRA, Gabriela Nunes. 2005. Estado e sociedade em Oliveira Vianna e Raymundo Faoro. Cadernos CRH, Salvador, v. 18, n. 44, pp. 223-227. 2008. Vinho novo em odres velhos: continuidade e mudança em

Os donos do poder. In: BOTELHO, André; BASTOS, Élide Rugai; 
BÔAS, Gláucia Villas. (orgs.). O moderno em questão: a década de 1950 no Brasil. Rio de Janeiro: Topbooks. pp.65-101.

SCHWARZ, Roberto. 1997. Duas meninas. São Paulo: Companhia das Letras. 2012. Ao vencedor, as batatas. São Paulo: Editora 34.

SCHWARTZMAN, Simon. 1975. São Paulo e o Estado nacional. São Paulo: Difel. 1988. Bases do autoritarismo brasileiro. 3. ed. Rio de Janeiro: Campus. . 2003. A atualidade de Raymundo Faoro. Dados, Rio Janeiro, v. 46, n. 2, pp. 207-213.

SILVA, Ricardo. 2008. Liberdade e lei no neo-republicanismo de Skinner e Pettit. Lua Nova, São Paulo, n. 74, pp. 151-194.

SOUZA, Jessé. 2000. A modernização seletiva. Brasília, DF: UnB. . 2015. A tolice da inteligência brasileira: ou como o país se deixa manipular pela elite. São Paulo: Leya.

WERNECK VIANNA, Luiz. 1997. A revolução passiva: iberismo e americanismo no Brasil. Rio de Janeiro: Revan. 1999. Weber e as interpretações do Brasil. Novos Estudos CEBRAP, São Paulo, n. 53, pp. 33-47. 2009. Raymundo Faoro e a difícil busca do moderno no país da modernização. In: BOTELHO, André; SCHWARCZ, Lilia. (orgs.). Um enigma chamado Brasil. São Paulo: Companhia das Letras. pp.364-377. . 2010. Entrevista dada a Gisele Araújo, Christian Lynch, Joelle Rouchou e Antonio Herculano. Escritos: Revista da Fundação Casa de Rui Barbosa, Rio de Janeiro, v. 4, n. 4, pp. 343-366. 


\section{RAYMUNDO FAORO E AS LINHAGENS DO PENSAMENTO POLÍTICO BRASILEIRO}

\section{LEONARDO OCTAVIO BELINELLI DE BRITO}

Resumo: $\mathrm{O}$ artigo parte da hipótese formulada por Gildo Marçal Brandão sobre a existência de "linhagens do pensamento político brasileiro", em especial a que denominou "idealismo constitucional", composta por autores que identificariam na suposta centralização política e administrativa do Estado luso-brasileiro o cerne explicativo da má formação social brasileira; em consequência, proporiam medidas políticas descentralizadoras e economicamente liberalizantes. Segundo Brandão, Raymundo Faoro seria um dos maiores exemplos desta linha de reflexão sobre o Brasil. Visando discutir essa tese, em termos sucintos argumentamos que há elementos na obra de Faoro que o aproximam desta linha de argumentação, mas há outros que dela o afastam, permitindo reinterpretar o sentido da sua contribuição ao pensamento político social e brasileiro e, por consequência, seu lugar nele.

Palavras-chave: Raymundo Faoro; Idealismo Constitucional; Pensamento Radical; Liberalismo Brasileiro.

\section{RAYMUNDO FAORO AND THE LINES OF BRAZILIAN POLITICAL THOUGHT}

Abstract: The article starts with the hypothesis formulated by Gildo Marçal Brandão on the existence of "lineages of Brazilian political thought", in particular the one he called "constitutional idealism", which is composed of authors who would find in the supposed political and administrative centralization of the Portuguese-Brazilian State the main explanatory point of Brazilian social malformation and, consequently, would propose decentralization and economically liberal political measures. According to Brandão, Raymundo Faoro 
would be one of the main examples of this line of thought on Brazil. In brief terms, we argue that there are elements in Faoro's work that approximate his ideas to this line of argumentation, but also elements that differ from it, allowing for reinterpreting the meaning of his contribution to Brazilian social and political thought and, consequently, its place in it.

Keywords: Raymundo Faoro; Constitutional Idealism; Radical Thought; Brazilian Liberalism.

Recebido: 31/03/2017_Aprovado: 18/03/2018 